\title{
Intuition and its effects on mathematical learning
}

\author{
Ashraf Babaei $^{1}$, Mehrnaz Chaiichi-Mellatshahi ${ }^{2}$ and Maryam Najafi ${ }^{2 *}$ \\ ${ }^{1}$ Department of Mathematics, Shahr-e Rey Branch, Islamic Azad University, Tehran, Iran \\ ${ }^{2}$ Department of Mathematics, Science and Research Branch, Islamic Azad University, Tehran, Iran \\ maryam0866@mailfa.org
}

\begin{abstract}
Intuition is the best instructional method in mathematics education. Using different method such as intuition, it makes promote learning in particular mathematics. Researchers have tried that studied and applied intuition method in mathematical learning and teaching field in present research. Then it is indicated snapshots of intuitive method for calculus. Sixty eight students are selected of first grade girl students at high school. Means of scores are studied via One-Sample Kolmogorov-Smirnov test, test of homogeneity of variances, ANOVA and Scheffe. The findings have shown that mathematical problems solving through intuition will have positive effects on the performance of students. Therefore it can conclude that intuitive method can ease problem solving process for students and this method motivates to learn and solve the difficult problems.
\end{abstract}

Keywords: Intuition, Mathematics, Learning, Problem solving, Teaching.

Introduction

During learning of mathematics, students face a wide range of new concepts. They need to integrate new mathematical aspects and develop pervious concepts. The most substantial work on intuition in mathematics education is that carried out by Fischbein (1987). In his view, intuition is a cognition characterized by the following features; self-evidence and immediacy (in that extrinsic justification is not needed), intrinsic certainly (note that self-evidence and certainly are not that same), perseverance (so that intuitions are stable), coerciveness, theory status, globality (in that intuitions offer a unitary global view), implicitness (so that although the result of selection, globalization and inference, intuitions will appear to be implicit). The behavioral task of intuition then is to prepare and guide our mental or practical activity. This links with Fischbein's further suggestion that there are "problem solving intuitions", for which, however he provides no empirical evidence. Noddings (1985) stated that if we seriously want to recognize the role of intuition in problem solving and virtually all mathematicians recognize its contribution- then we need to fill out this stage of representation with concrete accounts rather than detailed and pre specific theoretical accounts (Jones,1993). The Oxford dictionary defines "intuition" as: "(the power of) knowing without learning or reasoning". Intuitively, intuition may be conceived as selfevident, self-consisted, cognition. Some refer to intuition as a source of knowledge, while others refer to it as a method. According to Fischbein: "intuition is a ... crystallized - very often prematurely closed- conception in which incompleteness or vagueness of information is masked by special mechanisms for producing the feelings of immediacy, coherence and confidence"; immediacy- in the sense of intrinsic evidence, and coherence and confidence - in the sense of certitude (the feeling of certainty) (Giant, 2001). Fischbein (1987) examined students' individual concept formation and elaborated on how intuitive models influence the learning

Sci.Technol.Edu

Clndian Society for Education and Environment (iSee)

"Intuition based math learning"

http://www.indjst.org of mathematics: It is very well known that concepts and formal statements are very often associated, in a person's mind, with some particular instances. What is usually neglected is the fact that such particular instances may become, for that person, universal representatives of the respective concepts and statements and then acquire the heuristic attributes of models (Rösken \& Rolka, 2007). Bruner (1974) characterizes two alternative approaches to solving problems: in virtually any field of intellectual endeavour one may distinguish two approaches usually asserted to be different. One is intuitive, the other analytic ... in general intuition is less rigorous with respect to proof, more oriented to the whole problem than to particular parts, less verbalized with respect to justification, and based upon a confidence to operate with insufficient data (Tall, 1991). The existence of different modes of thought suggests a distinction between intuitive thought processes and the logical thought demanded by formal mathematics. Intuition involves parallel processing quite distinct from the step by step sequential processing required in rigorous deduction. An intuition arrives whole in the mind and it may be difficult to separate the components into a logical deductive order. Indeed, it is known that visual information is processed simultaneously; only the result of this processing is made available to the conscious self, not the process by which the gestalt is formed (Bogen, 1969; Gazzaniga, 1974). In schools, mathematical teaching and learning process is as way which students should know that most mathematical ideas can introduce with sensible, graphical and symbolic forms (Dafei, 2010). One of the most aims of mathematics education is the development of problem solving skills among students. Problem solving skills effect on success of students in mathematics and students which have not this skill, they do not very success in mathematics. Therefore current educational systems must follow other methods until students be able to conquest on failures in mathematical problems solving. 
In this research, we investigated the use of intuition in mathematical problem solving process.

Why do we use of intuition? problems better comprehend in many moments and we can estimate guesses for proving various sections of mathematical problems and theorems exactly. Such as guesses motivate to students and ease the problem solving process. Intuitive as visual representations or conceptual images can promote abilities of students in all mathematical texts. It is possible that people solve difficult problems or prove theorems correctly but same people comprehend same problems or theorems exactly. Intuition can be innate knowledge or sense without reasoning. Intuitive method is interesting for students and teachers. Teachers can explain and solve mathematical problems via intuition until students inform to real nature of problems. Here researchers have tried that studied and solve two items of calculus textbook through intuitive methods.

Problem: Find number of equation's solutions of $\mathrm{x}^{2}+2 \mathrm{x}-2=\frac{1}{\mathrm{x}}$.

Solve: First, we draw figure of $y=\frac{1}{x}$ then figure ofy $=x^{2}-$ $2 x-2$ (Fig.1). It can guess of figures that one of the solutions will be 1 and with replacing $x=1$ in equation, the correction of this guess has emphasized. Fig. 1 shows that this equation has two other solutions which are negative. If we want the precise value of solutions, firstly with multiplication a party of equation in $\mathrm{x}$, we write it as the form of $x^{3}+2 x^{2}-2 x-1=0$. Since polynomial $x^{3}+2 x^{2}-2 x-1=0$ is divisible on $x-1$. We have $x^{3}+$ $2 x^{2}-2 x-1=(x-1)\left(x^{2}+3 x+1\right)=0$. Then, $x=1$ and equation eases through intuitive method. In this Fig.1, students comprehend that this equation has not only solution (cross-location of two diagrams show that there are other solutions).

It seems that the comprehension of derivative is difficult for students. This subject can ease through intuitive method. Students must comprehend that derivative value is same tangent. For this reason, teacher can use of intuitive method. He can show that derivative is slope of tangent on $\mathrm{y}=\mathrm{f}(\mathrm{x})$ in $\mathrm{x}=\mathrm{x}_{0}$. We can estimate slope via line on two points of diagram. When $(a, f(a))$ is a point and $(a+h, f(a+h))$ is a other point of $y=f(x)$, tangent of this line is following as;

$m=\frac{f(a+h)-f(a)}{(a+h)-a}$

Then we have

$\mathrm{m}=\frac{\mathrm{f}(\mathrm{a}+\mathrm{h})-\mathrm{f}(\mathrm{a})}{\mathrm{h}}$

The selection of points which near to tangent point, it can
Intuitive comprehension helps us mathematical $x=\frac{-3 \pm \sqrt{5}}{2}$ are main solutions. The solution of cited

Vol. 5 No. 7 (July 2012)

ISSN: 0974- 6846

get to slope of tangent exactly. If $h \rightarrow 0$, then this line is converted to tangent line on diagram and derivative of function $\mathrm{f}$ in $\mathrm{x}=\mathrm{a}$ is following as;

$f^{\prime}(a)=\lim _{h \rightarrow 0} \frac{f(a+h)-f(a)}{h}$

The comprehension of derivation concept via intuition can make deep learning in this field. For example, students notice that derivative of constants equal to zero because when students draw $y=c$, they will observe that this diagram has not any slope then derivative of constants are zero (Fig.2).

Literature

Many years ago, there are a variety of descriptions of the meaning and nature of intuition. Bruner (1974) contrasts intuition with analytic thinking, Poincaré (1913)

Fig. 1. Snapshot of intuitive sample; solutions of equation

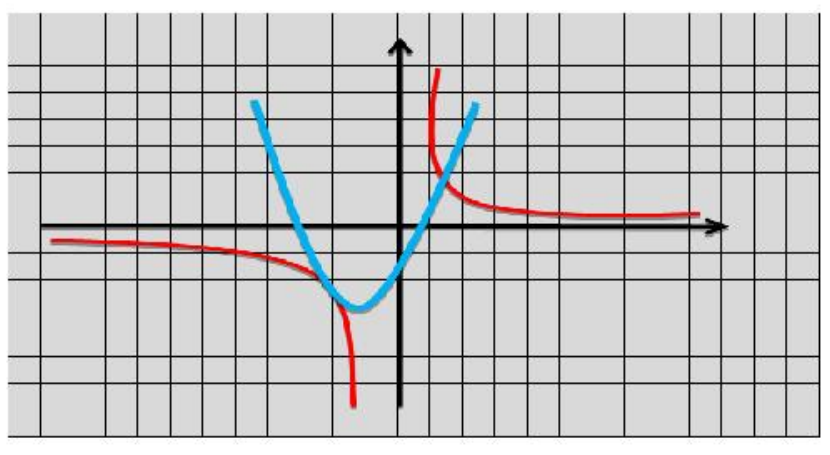

Note: $-\mathrm{Y}=(\mathrm{x}+\mathbf{1})^{2}-3$ and $\mathbf{V}: \mathrm{Y}=\frac{\mathbf{1}}{\mathrm{x}}$

Fig.2. Snapshot of intuitive sample; nature of derivative

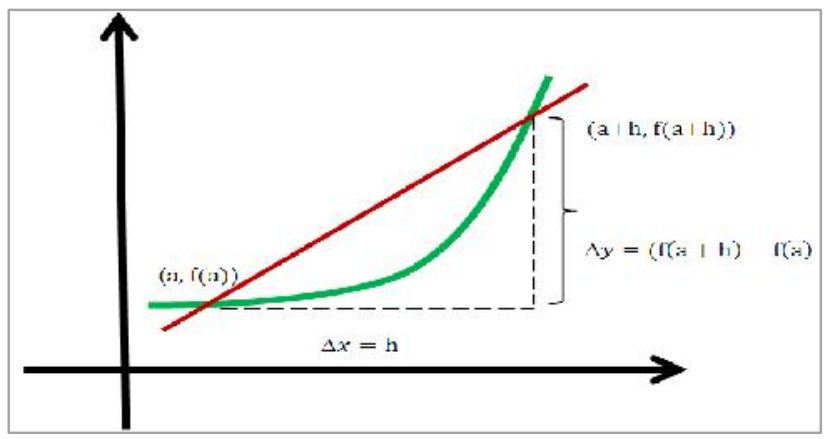

Fig.3. The comparison of scores' means

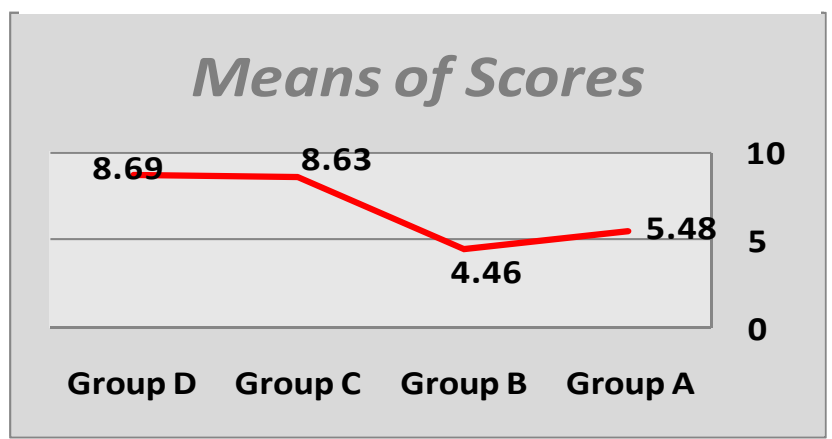

Sci.Technol.Edu

CIndian Society for Education and Environment (iSee) 
contrasts intuition with logic, as does Hadamard (1945), whilst differing with Poincaré over important details. Skemp (1971) contrasts intuitive and reflective thinking as different modes of mental activity and subsequent work (Skemp,1979) differs quite considerably from Poincaré's description (Tall, 1980). Also Fujita et al. (2004) stated and researched about intuition in Geometry with title "geometrical intuition and the learning and teaching of geometry". They believed that intuition is often regarded as essential in the learning of geometry, but how such skills might be effectively developed in students remains an open question. Their paper reviews the role and importance of geometrical intuition and suggests it involves the skills to create and manipulate geometrical figures in the mind, to see geometrical properties, to relate images to concepts and theorems in geometry, and decide where and how to start when solving problems in geometry. This method contributes to developing students' geometrical intuition (Fujita et al., 2004). Watson (2000) studied the research entitled "Preservice mathematics teachers' understanding of sampling: intuition or mathematics". He considered 33 pre-service secondary mathematics teachers' solutions to a famous sampling problem, well known for confounding educated adults. Of particular interest is the use of intuition and/or formal mathematics in reaching a conclusion. The relationships of solution strategy to students' background in formal mathematics and to gender are also considered. Finally he explained that it is essential that pre-service mathematics education programs provide students with problem situations where erroneous conclusions may result, either due to natural intuition without previous mathematical experience or due to faulty calculations without intuition. Zaree (2010) studied and evaluated the research about intuition and its role in mathematics education. She cited that intuition is one of the most secret and ambiguity conceptions in mathematics and has special efficiency and application in mathematical problem solving instruction. In her research, it is used of this instructional method for better projection of trigonometry proportions, first degree equations and linear equation through drawing mathematical problems. The results show that use of intuitive instruction method in mathematics increase to students' capacity of problem solving.

Hypothesis

Mathematical problems solving through intuition will have positive effects on the performance of students.

Methodology

This present research method is causal-comparative. In this research method, researchers tried to find

Table 1. Descriptive statistic of data

\begin{tabular}{|l|c|c|c|c|}
\hline & GROUP A & GROUP B & GROUP C & GROUP D \\
\hline $\mathrm{N}$ & 16 & 16 & 18 & 18 \\
\hline Mean & 5.48 & 4.46 & 8.63 & 8.69 \\
\hline Mode & 6.00 & 2.75 & 8.5 & 10 \\
\hline Variance & 4.13 & 4.29 & 1.36 & 1.46 \\
\hline
\end{tabular}

Sci.Technol.Edu

(C)Indian Society for Education and Environment (iSee)

"Intuition based math learning"

http://www.indjst.org
Vol. 5 No. 7 (July 2012)

ISSN: 0974- 6846 relationship among variables and determine the reasons for or the causes of the current status of the phenomenon under investigation. Really it is tried that investigate possible cause-effect relationships by observing existing consequences and searching back through the data for plausible causal factors. In causal-comparative method, researchers tried to find out what factor has led to the observed difference on some dependent variables. Independent variable (intuitive instruction method) has already occurred and independent variable cannot manipulate. Two groups (usual and intuitive instruction groups) are already formed in this research. Researchers haven't control over the events in other words, researchers appears on the scene after all events have occurred. To above reasons, researchers used of this method, because all events had occurred already. Regard to this method, two groups; A, B are usual groups that researchers have taught through usual methods for calculus. In addition groups; C, D are groups which were taught under intuitive methods. Level of four groups was same. After implementing intuitive and usual instruction methods in four groups, researchers have performed "calculus exams" in four groups. This exam has 5 questions. General score was 10. These questions include of equations, trigonometry, limit, integral and derivative. This exam is confirmed via mathematics professors and its content reliability is proved with 90 percent through Split-half test.

\section{Participants}

In present research, statistical society was two girly high schools. Thereby cluster sampling two groups are selected of each high school. These four groups were first grades of high school. General numbers equals to 68 students. All students have same conditions.

\section{Data analysis methods}

In descriptive statistic section of this research is used of mean, mode, variance, minimum and maximum. For deductive statistic section, it is used of One-Sample Kolmogorov-Smirnov test, test of homogeneity of variances, ANOVA and Scheffe test in meaningful level of 0.05 .

Results

As shown in Table 1 , means of groups $C$ and $D$ are more than groups $A$ and $B\left(M_{A}=8.63, M_{B}=8.69\right)$. In addition frequency of score 10 is the highest rate in group $D$ rather other groups (Mode $D=10$ ). Also the least variance belongs to group $C$ (Variance $\left.{ }_{C}=1.36\right)$. In Fig.3, line of groups $C$ and $D$ is higher than group $A$ and $B$. Level of groups A and B are same.

Firstly for testing respected hypothesis, researchers have used of One-Sample Kolmogorov-Smirnov test, test of homogeneity of variances respectively. The results of One-Sample Kolmogorov-Smirnov test shown that data are normal $(P>0.05)$ also test's findings of homogeneity of variances have indicated that variances are equal $(P>0.05)$. Then it can apply parametric test; ANOVA and Scheffe. 
Table 2. Results of ANOVA

\begin{tabular}{|l|c|c|c|c|c|}
\hline & $\begin{array}{c}\text { Sum of } \\
\text { Squares }\end{array}$ & df & Mean Square & $F$ & Sig. \\
\hline Between Groups & 215.59 & 3 & 71.86 & 19.05 & 0.000 \\
\hline Within Groups & 245.09 & 65 & 3.77 & & \\
\hline Total & 460.68 & 68 & & & \\
\hline
\end{tabular}

Table 3. Results of Scheffe

\begin{tabular}{|c|c|c|c|c|c|c|}
\hline \multirow{2}{*}{ VAR 1} & \multirow{2}{*}{ VAR 2} & \multirow{2}{*}{$\begin{array}{c}\text { Mean } \\
\text { Difference }\end{array}$} & \multirow{2}{*}{$\begin{array}{l}\text { Std. } \\
\text { Error }\end{array}$} & \multirow{2}{*}{ Sig } & \multicolumn{2}{|c|}{$\begin{array}{c}95 \% \text { Confidence } \\
\text { Interval }\end{array}$} \\
\hline & & & & & $\begin{array}{l}\text { Lower } \\
\text { Bound }\end{array}$ & $\begin{array}{l}\text { Upper } \\
\text { Bound }\end{array}$ \\
\hline \multirow{3}{*}{ GROUP A } & GROUP B & 1.01 & 0.68 & 0.53 & -0.95 & 2.98 \\
\hline & GROUP C & -2.69 & 0.65 & 0.002 & -4.59 & -0.8 \\
\hline & GROUP D & -3.21 & 0.66 & 0.000 & -5.12 & -1.29 \\
\hline \multirow{3}{*}{ GROUP B } & GROUP A & -1.01 & 0.68 & 0.53 & -2.98 & 0.95 \\
\hline & GROUP C & -3.71 & 0.65 & 0.000 & -5.6 & -1.82 \\
\hline & GROUP D & -4.22 & 0.66 & 0.000 & -6.14 & -2.31 \\
\hline \multirow{3}{*}{ GROUP C } & GROUP A & 2.69 & 0.65 & 0.002 & 0.8 & 4.59 \\
\hline & GROUP B & 3.71 & 0.65 & 0.000 & 1.82 & 5.6 \\
\hline & GROUP D & -0.51 & 0.63 & 0.88 & -2.34 & 1.32 \\
\hline \multirow{3}{*}{ GROUP D } & GROUP A & 3.21 & 0.66 & 0.000 & 1.29 & 5.12 \\
\hline & GROUP B & 4.22 & 0.66 & 0.000 & 2.31 & 6.14 \\
\hline & GROUP C & 0.51 & 0.63 & 0.88 & -1.32 & 2.34 \\
\hline
\end{tabular}

The results of ANOVA test has shown (Table 2) that there are significant differences among four groups $(P<0.05)$. Theses significant differences must study thereby Scheffe test exactly. In Scheffe test, means' differences of four groups are studied exactly. There is significant difference between group $\mathrm{C}$ and groups $\mathrm{A}, \mathrm{B}$ $(P<0.05)$. Also as it is shown in Table 3 , there is significant difference between group $D$ and groups $A, B$ $(P<0.05)$. Therefore it can conclude that means of group $C$ and $D$ are more that group $A$ and $B$ regard to mean differences.

\section{Conclusion}

Intuition has key role in finding the solution of problem and comprehension of problem's content. Usually presentation of a problem through figure or intuitive method leads to facilitate, collect and coherent related information to problem and considers to the relations of among items in mathematical problem. The results of this research show that mathematical problems solving through intuition will have positive effects on the performance of students. It can analyze reasons of it in this phrases; observation of problems via intuitive method will have calmness and hearty trustful. Therefore, students can better think to problems and they can solve it. Using intuitive instruction and use of intuition and upbringing intuitive perception can enable students in exact perception of proofs and development of abstract thinking which is the final aim of mathematics learning. Students will have more strategies and instruments for problem solving. Student will enable perforate to center of formulas and problems through observation of examples, figures, the study of particular and sample cases of earlier experiences and self-activities. Usage intuitive method helps to student that became creative person and provides similar examples and applications then student 367-382. Penguin. increase capacity of modeling and analysis. Suggestions introduce to next researches; 1) intuitive instruction methods shall teach to teachers, 2) the effect of intuition shall consider on base of meta-cognition method and 3 ) such research shall do for others subjects and lessons.

Limitations of this research are included of; 1) this research limited to high school and 2) this research limited to mathematics.

\section{References}

1. Bruner JS (1974) Towards a disciplined intuition. Relevance of education. Penguin. pp: 98-113.

2. Bogen JE (1969) The other side of the brain: 2. an appositional mind. Bulletin of the Los-Angeles Neurol. Soc. 34, 135-162.

3. Dafei H (2010) Multiple representations in mathematics education. Maths Edu., Magaz, Edu.,Res.\&Prog.Org.Edu,.Edu.,Publ.pp:74-79

4. Fischbein E (1987) Intuition in science and mathematics: an educational approach. Dordrecht: Reidel.

5. Fujita T, Jones K and Yamamoto Sh (2004) Geometrical intuition and the learning and teaching of geometry. Presented to Topic Study Group 10 (TSG10) 10th Intl. Congress on Mathematical Edu. (ICME10). Copenhagen, Denmark. pp: 4-11.

6. Giant D (2001) Misleading intuition in algorithmic problem solving. CS Group, science education department Tel-Aviv University, Israel. SIGCSE: 2/01 Charlotte, NC USA.

7. Gazzaniga MS (1974) Cerebral dominance viewed as a decision system. In: Hemisphere Function in the Human Brain, Dimond S. \& Beaumont J (ed.), Elek, London. pp:

8. Hadamard J (1945) The Psychology of Invention in the Mathematical Field. Reprinted Dover.

9. Jones K (1993) Researching geometrical intuition. Proc. British Soc. Res. Learning Maths. 13(3), 15-19.

10. Noddings N (1985) Research in small groups. Silver, EA (Ed.), teaching and learning mathematical problem solving. Hillsdale, NJ: Lawrence Erlbaum Associates.

11. Poincaré H (1913) Mathematical creation. Foundations of Sci. NY: The Science Press.

12. Rösken B, and Rolka K (2007) Integrating intuition: the role of concept image and concept definition for students' learning of integral calculus. Montana Council of Teachers of Maths. Montana Maths. Enthusiast, Monograph. 3, 181-204.

13. Skemp RR (1971) The psychology of learning mathematics.

14. Skemp RR (1979) Goals of learning and qualities of understanding. Proc. 3rd Intl. Conf. for the Psych. of Maths. Edu. PP 197-202.

15. Tall $D$ (1991) Intuition and rigor: the role of visualization in the calculus. In: Visualization in Mathematics. Zimmermann \& Cunningham (ed.), M.A.A. 19, 105-119.

16. Tall D (1980) Mathematical intuition, with special reference to limiting processes. Proc. $4^{\text {th }}$ Int. Conf. Psychol. Maths. Education, Berkeley. pp: 170-176.

17. Watson J (2000) Pre-service mathematics teachers' understanding of sampling: intuition or mathematics. Univ. Tasmania. Maths. Teach. Edu. \& Develop. 2, 121-135.

18. Zaree Q (2010) Role of intuition in mathematics education. Master Dissertation, Fars Univ., Iran. pp: 5-43. 